\title{
Japan's efforts to promote global health using satellite remote sensing data from the Japan Aerospace Exploration Agency for prediction of infectious diseases and air quality
}

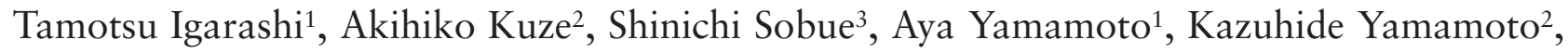 \\ Kei Oyoshi², Keiji Imaoka², Toru Fukuda ${ }^{2}$ \\ ${ }^{1}$ Research and Development Department, Remote Sensing Technology Center of Japan, 3-17-1 Toranomon, \\ Minato-ku, Tokyo, Japan; ${ }^{2}$ Earth Observation Research Center, Japan Aerospace Exploration Agency, Tsukuba, \\ Ibaraki, Japan; ${ }^{3}$ Planning Department, Remote Sensing Technology Center of Japan, 3-17-1 Toranomon, \\ Minato-ku, Tokyo, Japan
}

\begin{abstract}
In this paper we review the status of new applications research of the Japanese Aerospace Exploration Agency (JAXA) for global health promotion using information derived from Earth observation data by satellites in cooperation with inter-disciplinary collaborators. Current research effort at JAXA to promote global public health is focused primarily on the use of remote sensing to address two themes: (i) prediction models for malaria and cholera in Kenya, Africa; and (ii) air quality assessment of small, particulate matter $\left(\mathrm{PM}_{2.5}\right)$, nitrogen dioxide $\left(\mathrm{NO}_{2}\right)$ and ozone $\left(\mathrm{O}_{3}\right)$. Respiratory and cardivascular diseases constitute cross-boundary public health risk issues on a global scale. The authors report here on results of current of a collaborative research to call attention to the need to take preventive measures against threats to public health using newly arising remote sensing information from space.
\end{abstract}

Keywords: Earth observation satellites, environment, infectious diseases, air quality, respiratory disease, cardiovascular disease, Japan.

\section{Introduction}

Recent public health research efforts at the Japanese Aerospace Exploration Agency (JAXA) has focused on new data from Japan's space program to address two themes of infectious diseases and air quality. For the infectious diseases theme, the Earth Observation Research Center (EORC), JAXA and the Institute of Tropical Medicine of Nagasaki University (NEKKEN) have been engaged in collaborative research on malaria and cholera in Kenya from 2012 to 2014. In the beginning phase of the research, the authors found positive proof of the relationship between epidemics and climatic events (Hashizume et al., 2009, 2011; Collins et al., 2011; Minakawa et al., 2012). Data from satellite sensing, health informatics and demographic surveillance (HDSS) were analyzed to produce integrated datasets for correlation analysis to identify

\footnotetext{
Corresponding author:

Tamotsu Igarashi

Research and Development Department

Remote Sensing Technology Center of Japan

3-17-1 Toranomon, Minato-ku, Tokyo, Japan

Tel. +81 3 6435-6739; Fax +813 5777-1581

E-mail: igarashi_tamotsu@restec.or.jp
}

processes or mechanisms that may relate to malaria and cholera incidence in Kenya. Environmental change processes studied included monthly and yearly changes in (i) rainfall as measured by the Global Satellite Mapping of Precipitation program (GSMaP); (ii) lake level change measurements by satellite-borne altimetry; (iii) coverage of aquatic plants prevalent over lakes observed by satellite images; and (iv) the distribution of mosquito larvae habitats by ground truth surveys.

For the air quality theme, monitoring of atmospheric constituents such as ozone $\left(\mathrm{O}_{3}\right)$ satellite observation systems data from Japan was initially limited to observations in the upper atmosphere by well documented optical remote sensing techniques (Sasano et al., 1999) using spectrometers. However, tropospheric measurements are difficult as it is the lowest portion of Earth's atmosphere and thus far from the orbit of the satellite, solar light is multiply-scattered by dense molecules and aerosols, and clouds interfere with incident solar light. Troposphere-oriented remote sensing must this detect and correct for cloud and aerosol effects.

Air quality in the lower troposphere is essential for human health, where fine, particulate matter $\left(\mathrm{PM}_{2.5}\right)$, tropospheric ozone $\left(\mathrm{O}_{3}\right)$ and nitrogen dioxide $\left(\mathrm{NO}_{2}\right)$ are major health-relevant pollutants (WHO, 2006). 
Tropospheric $\mathrm{O}_{3}$ impacts both humans and vegetation and is controlled by $\mathrm{NO}_{2} \cdot \mathrm{PM}_{2.5}$ can be estimated by relating it to observed Aerosol Optical Depth (AOD) from space (van Donkelaar et al., 2006). The Moderate Resolution Imaging Spectroradiometer (MODIS) and the Multi-angle Imaging Spectro Radiometer (MISR) instruments onboard the Terra and Aqua satellites have a demonstrated capability to monitor $\mathrm{PM}_{2.5}$. Space-borne ultraviolet (UV)-Visible (V) spectrometers from the Global Ozone Monitoring Experiment (GOME), GOME-2 that includes the Scanning Imaging Absorption Spectrometer for Atmospheric ChartographY (SCIAMACHY) of the European Space Agency (ESA) and the Ozone Measuring Instrument (OMI) of NASA have been used to monitor $\mathrm{O}_{3}$ and $\mathrm{NO}_{2}$ (Burrows et al., 1995; Munro et al., 2006; Boersma et al., 2011). Compared with stratospheric components and long-life greenhouse gases in the troposphere, air pollutants in the troposphere are short-lived and their emission sources

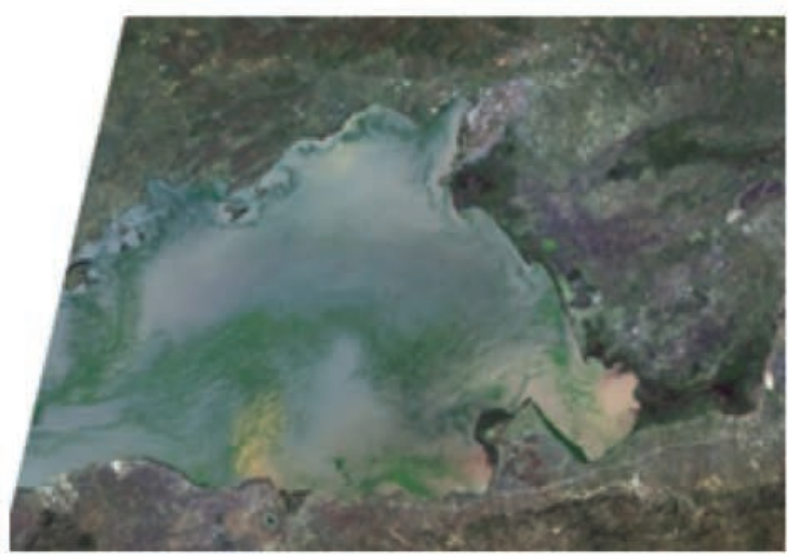

(a) 12 November 2008 are localised. Therefore, appropriate spatial resolution and imaging capability are required in addition to cloud detection. Imaging spectrometer technology has not yet matured to the stage of launching satellite instruments into geo-stationery orbits that are ideal for monitoring purposes. In this paper, we discuss the potential for improvements in air pollution monitoring from space.

\section{Infectious diseases}

Lake Victoria, the second largest fresh-water lake in the world, with an area of $69,485 \mathrm{~km}^{2}$, is the source of the Nile River and the water supply for the residents around the lake in Uganda, Tanzania and Kenya. In the Winam Gulf, located in the north-eastern part of the lake outbreaks of water hyacinth overgrowth have been observed since 1998 that sometimes block sailing fishing boats from leaving and arriving in harbors. Algae blooms of Microcystis cyanobacteria (blue-green

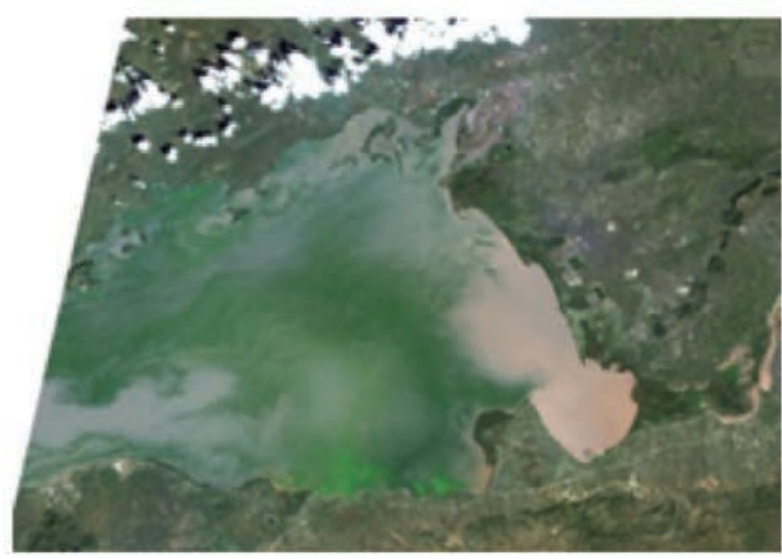

(b) 31 December 2009

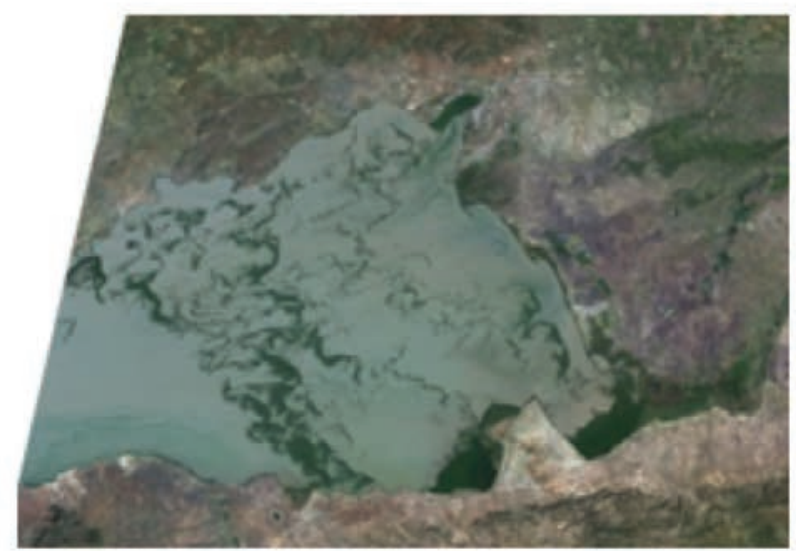

(c) 3 January 2011

Fig. 1. Nutrient-rich sediments and floating weeds with water hyacinths in Winam Gulf, Lake Victoria (ALOS AVNIR-2) images. 
algae) also appear frequently on the water surface which are indicators of polluted water quality. Hyacinths, floating weeds and algae blooms are fed by the nutrition-rich water flow into the lake from the river basin and surrounding fertilised agricultural fields.

Preliminary investigations by JAXA on the recent status of environmental change in Lake Victoria using archived image datasets of the Advanced Visible and Near Infrared Radiometer type 2 (AVNIR-2) sensor onboard the Advanced Land Observing Satellite (ALOS), reveal the greenish patterns on the water of Winam Gulf. In this region, two wet seasons occur annually in March to June and October to November, but can vary from one year to the next. The observations on 12 November 2008 (a) and on 31 December 2009 (b) that show turbid water zones around the river mouths on the southern and eastern lakeshore. In the image of 3 January 2011 (c), 1-2 months later than the prior observations (on an annual basis), turbidity was weaker than that seen in 2008 and 2009.

The turbididty in Winam Gulf is attributed to suspended sediments coming from the rivers after the rainfall of the wet season (October to November). The green patterns over areas covered by water are attributed to water hyacinths and Microcystis algae blooms, which are reported to be indicators of conditions suitable for cholera and the mosquito vectors (Anopheles) that transmit malaria outbreaks (Hashizume et al., 2009, 2011).

JAXA and Nagasaki University set a field data transmitter at datalogger station on the Lake Victoria lakeshore at the International Centre of Insect Physiology and Ecology (ICIPE), Mbita, Kenya from
May 31 to June 9 of each year changes were monitored in water surface coverage with (i) water hyacinths and Microcystis; (ii) water level; and (iii) water color using stationary field cameras were monitored to validate information derived from satellite remote sensing data (Fig. 2).

From January 24 to February 2 2013, JAXA and Nagasaki University initiated a cooperative field survey at Lake Victoria to select the best out of several candidate points along a 100-km lakeshore to record ground truth observations over a one year period on lake water quality and aquatic vegetation, mainly floating weeds, such as water hyacinths and Microcystis considered to be associated with cholera outbreaks and habitats suitable for the larvae of the anopheline mosquito vectors of malaria. In addition to monitoring aquatic vegetation, environmental factors affecting growth processes and changes in distribution were monitored from space using a pan-sharpened image of AVNIR-2 with a spatial resolution of $10 \mathrm{~m}$, and PRISM, onboard ALOS with a spatial resolution of $2.5 \mathrm{~m}$. The normalized difference vegetation index (NDVI) was monitored using MODIS at the 250-m resolution. A point on the western coast of Mbita (upper right corner of Fig. 3) was selected as the most appropriate location to monitor changes in water level, surface water quality and aquatic plants which are important factors in lagoon generation and disappearance.

The inset image shows a full size scene of an ALOS pan-sharpened image of AVNIR-2 while the full expanded picture of the rectangle in the insert has $10-\mathrm{m}$ spatial resolution obtained on 5 December 2010 with PRISM data, while the full expanded picture of the rectangle in the insert has a $2.5-\mathrm{m}$ spatial resolution.


Fig. 2. Field and instruments for weather observation instruments on the Lake Victoria study site at the International Centre of Insect Physiology and Ecology (ICIPE), Mbita, Kenya. Field data transmitter with weather observation instruments (left) and lake view (right). 


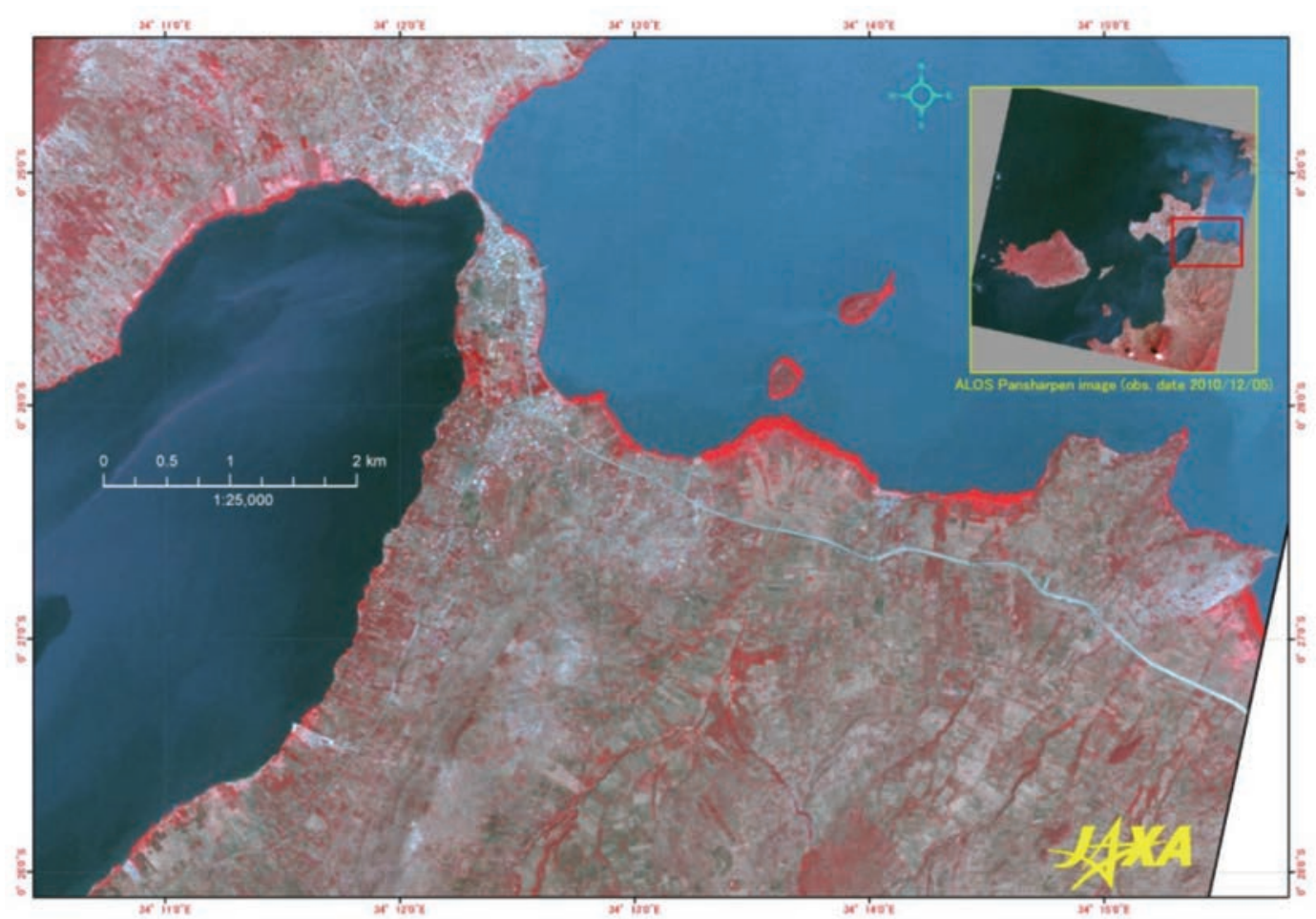

Fig. 3. Mapping water hyacinth mats and possible lagoon areas where there are potential mosquito larvae habitats. ALOS pan-sharpened false colour image of a part of Lake Victoria showing inlets separated by a road between the Rusinga Island and the southwestern lakeshore of Mbita District in the western part of Kenya.

The red rectangular area shows the coverage area of the expanded Fig. 3 image.

When environmental factors, weather conditions and climate variability are thought to be affecting the incidence of infectious diseases, significant influential factors should be identified through time series data analysis. For the cholera study, water hyacinth and Microcystis surface coverage, ground and water surface temperature, water colour (reflecting water quality), rainfall and solar radiation were considered the most important factors affecting the ecosystem. For the malaria study, rainfall, water level, deforestation, land cover change, ponds/wetlands, lagoons and hyacinths on the lakeshore were the important factors used to monitor the potential habitats of anopheline mosquito larvae that indicate malaria transmission. For this purpose, medium resolution sensors like MODIS and the Second-generation the Global Imager (SGLI) onboard Global Change Observation Mission-Climate (GCOM-C), which is planned to be launched by JAXA in 2016, are expected to deliver useful sources of data.

The MODIS time-series datasets can be used to obtain a comprehensive evaluation of regional environment change in research programmes. The data products shown in Table 2 are proposed as necessary to estimate environmental conditions for malaria and cholera.
MODIS data around Japan were received from the Earth Observation Center of JAXA (EOC) and Tokai University Research and Information Center (TRIC): http://kuroshio.eorc.jaxa.jp/ADEOS/mod_nrt_new/in dex.html and the JAXA Satellite Monitoring for Environmental Studies (JASMES): http://kuroshio. eorc.jaxa.jp/JASMES/index.html.

The number of pixels with a NDVI values less than 0.2 in Fig. 4 seems to be almost constant for most of the year while the number of pixels with high NDVI tends to increase on May and June every year during the dry season. In 2007, the ratio of NDVI less than 0.2 showed the minimum value, indicating the NDVI being at its highest value due to the increase of water hyacinth coverage of the lake water surface.

Now in the second year period of JAXA-Nagasaki University cooperative research, satellite remote sensing data have been explored and reviewed in this paper. In the next step, the research focus will be on the development of forecast models on incidence of infectious diseases in relation to environmental factors, using satellite remote sensing data of cloud cover, land surface temperature, soil moisture and vegetation cover by MODIS, rainfall mapping by GSMaP and lake water level time series datasets by TOPEX/Poseidon, Jason-1, 2 and OSTM during 1992 to 2014. 
Table 1. Satellites and on-board sensors useful for environmental research on health.

A. Infectious diseases

\begin{tabular}{lll}
\hline Satellite & Sensor & Objective \\
\hline The Advanced Land Observing Satellite & The Advanced Visible Near Infrared & Vegetation, water colour, soil \\
(ALOS) (operated from 2006 to 2011) & Radiometer type 2 (AVNIR-2)
\end{tabular}

(ALOS) (operated from 2006 to 2011)

The Advanced Land Observing Satellite (ALOS) (operated from 2006 to 2011)

The Panchromatic Remote-sensing Instrument for Stereo Mapping (PRISM)²

The Earth Observing System (EOS) Terra (EOS PM)/Aqua (EOS AM) (operating from 1999 (Terra) and 2002 (Aqua)

Ocean Topography Experiment (TOPEX/POSEIDON)/Jason-1, OSTM 2/ (operating from 1992)

Global Satellite Mapping of Precipitation (GSMaP) (data observed from 2000)

B. Air quality

Satellite Sensor

Rain radar, radiometer, sounder ${ }^{6}$

0.1 deg grid (updated hourly) product

Altimeter $^{5} \quad$ Lake water level
Lagoons, ponds, residential areas, digital terrain mode with $5-\mathrm{m}$ resolution

Cloud mask, NDVI, turbidity, vegetation

The Thermal and Near infrared Sensor for Greenhouse gases carbon Observation-Cloud and Aerosol Imager (TANSO-CAI)

The Greenhouse gases Observing SATellite (GOSAT) (operating from 2009)

The Greenhouse gases Observing SATellite (GOSAT) (operating from 2009)

The Thermal and Near infrared Sensor for

Aerosols, clouds carbon Observation-Fourier Transform Spectrometer (TANSO -FTS) ${ }^{7}$

The Global Change Observation Mission-Climate (GCOM-C) satellite (planned launch for 2016)

The Earth Cloud, Aerosol and Radiation Explorer (EarthCARE) ${ }^{9}$ (planned launch for 2016)

GOSAT-210 (planned launch for 2018)

The second-generation Global Imager $(\mathrm{SGLI})^{8}$

Aerosols over ocean and land, clouds

Cloud Profiling Radar (CPR), Atmospheric Clouds, aerosols (horizontal/vertical), Lidar (ATLID), Multi-Spectral Imager (MSI), radiation Broadband Radiometer (BBR)

TANSO-CAI-2, TANSO-FTS-2

$\mathrm{PM}_{2.5}$, aerosols greenhouse gases
${ }^{1}$ http://www.eorc.jaxa.jp/ALOS/en/about/avnir2.htm; ${ }^{2} \mathrm{http}: / /$ www.eorc.jaxa.jp/ALOS/en/about/prism.htm ${ }^{3} \mathrm{http}: / /$ modis.gsfc.nasa.gov/data/dataprod/index.php ${ }^{4}$ http://kuroshio.eorc.jaxa.jp/JASMES/index.html ${ }^{5} \mathrm{http}: / /$ www.pecad.fas.usda.gov/cropexplorer/global_reservoir/gr _regional_chart.aspx?regioni=eafrica\&reservoir_name=Victoria

Table 2. MODIS product and derived information.

\begin{tabular}{ll}
\hline MODIS & Scene description \\
\hline Cloud mask & Clear sky pixel identification \\
NDVI & $\begin{array}{l}\text { Water surface with or without } \\
\text { vegetation }\end{array}$ \\
Ch. 1 Reflectance & Turbidity, Microcystis \\
Ch. 31 Brigthness, temperature & Vegetation productivity \\
\hline
\end{tabular}

\begin{abstract}
${ }^{6}$ http://sharaku.eorc.jaxa.jp/GSMaP/index.htm ${ }^{7}$ http://www.gosat.nies.go.jp/index_e.html ${ }^{8} \mathrm{http}: / /$ suzaku.eorc.jaxa.jp/GCOM/index.html ${ }^{9} \mathrm{http}: / /$ www.eorc.jaxa.jp/EARTHCARE/index.html ${ }^{10} \mathrm{http}: / / w w w . g o s a t . n i e s . g o . j p / i n d e x \_e . h t m l$
\end{abstract}

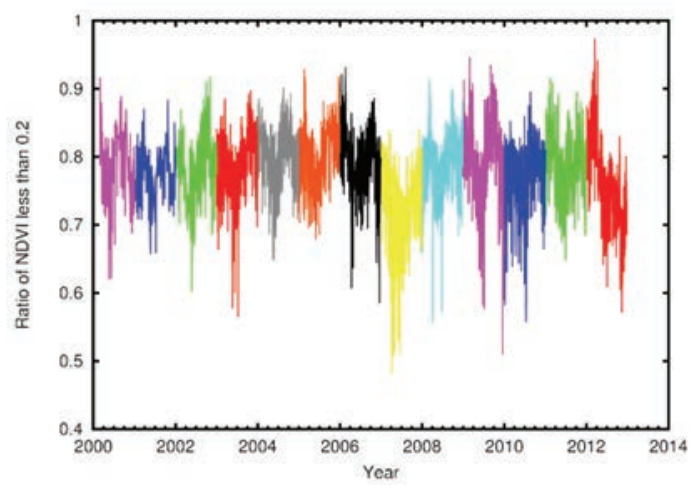

Fig. 4. NDVI values less than 0.2 derived from Ch.1 (Red) and Ch. 2 (NIR) of MODIS products of land surface reflectance with 250$\mathrm{m}$ spatial resolution and cloud mask with 1-km spatial resolution. Source: Moriyama Lab., Graduate School of Eng., Nagasaki University (Terra: 2000/03 - 2012/12, Aqua: 2002/07 - 2012/12). 


\section{Air quality}

Aerosols, a term covering the dispersion of colloid particles in the air (though we discuss also various kinds of polluting molecules under the air quality heading), in the atmosphere have different sizes, shapes, and components with differing impacts on human health.

In this section, we discuss the observation of aerosols remotely from space using optical instruments. There are many optically equivalent parameters that characterise aerosol distribution. For molecules, however, the parameter that must be measured from space is column density only. Each molecule has its unique absorption spectral lines and their cross sections can be characterised by laboratory spectroscopy. The quantity of individual molecules in the column is directly measured by selected spectral bands using spectrometers. Here we discuss the observation methods for aerosols and molecules separately.

JAXA launched and is operating Greenhouse gases Observing SATellite (GOSAT) in 2009 which is the first satellite to mainly observe greenhouse gases (Kuze et al., 2009). The major challenge of GOSAT is accurate monitoring of atmospheric constituents near the Earth's surface from space. Aerosol scattering changes the effective optical-path-length between the Sun, the Earth's surface and the satellite, and it has to be estimated to minimise uncertainty for $\mathrm{CO}_{2}$ and $\mathrm{CH}_{4}$ retrieval. Its follow-on GOSAT-2 adds $\mathrm{PM}_{2.5}$ monitoring as one of its main mission objectives by improving aerosol measurements over land by addition of UV and visible channels to its cloud and aerosol imager (Thermal And Near infrared Sensor for carbon Observation Cloud and Aerosol Imager-2 (TANSOCAI-2)).

In 2016, JAXA is scheduled to launch the Global change observation mission (GCOM)-C with the Second-generation Global Imager (SGLI) to observe both land and ocean aerosols using UV (380 nm) and polarisation channels. It will also have the capability to view the target from different view angles. JAXA and the ESA will jointly launch Earth Clouds, Aerosols and Radiation Explorer (EarthCARE) (http://global. jaxa.jp/projects/sat/earthcare/a), which is designed to provide three-dimensional distributions of clouds and aerosols as well as assessment of the chemical properties of aerosols.

When we observe aerosols by optical remote sensing, optically equivalent physical parameters that can be retrieved from space must be modeled by radiation transfer calculations. Space-borne instruments can measure radiance-spectra scattered and absorbed by aerosols at the top of the atmosphere. When the instruments view the same target from different directions, the phase function, which represents reflected intensity as a function of angle, can be characterised. Scattering and absorption are dependent on aerosol related parameters such as $\mathrm{AOD}$, index of refraction (both real and imaginary parts), height size and distribution. Among these optically equivalent parameters, some can be retrieved but others have to be assumed by models. The TANSO-Fourier-Transform Spectrometer (FTS) the main instrument onboard GOSAT, is unique. It covers a wide spectral range with three spectral bands in shortwave infrared (SWIR) range measuring two liner polarisation simultaneously with high spectral resolution. By observing oxygen absorption at $760 \mathrm{~nm}$ (the $\mathrm{O}_{2} \mathrm{~A}$ band), the effective optical-path-length between the sun, the Earth's surface and the satellite is well retrieved. With surface pressure information, cloud and aerosol height information, the path length can be estimated, since it is modified by these parameters. Using the 2-axes pointing mechanism of TANSO-FTS it is possible to view the same target from different directions. These functions allow estimation of the amount, particle size distribution, height and distribution as well as particle type and absorption/scattering characteristics (Frankenberg et al., 2012). Two simultaneous linear polarisation measurements might detect higher polarised scattering by aerosols than reflection at the Earth's surface. However, this quantitative analysis requires complicated instruments, Mueller matrises and Stokes vector calculations of the spectral radiance at the top-of-the atmosphere. Further study is needed on the usage of polarisation. Existing optical instruments only provide the information on AOD and its spectral dependency, which is usually expressed as an Angstrom exponent. TANSO-FTS on GOSAT is a precursor for advanced aerosol observation from space.

One of the important in-situ parameters that can be observed locally at the Earth's surface is mass per volume of $\mathrm{PM}_{2.5}$, while satellite remote sensing measures this parameter by its optical scattering properties. The relationship between mass of $\mathrm{PM}_{2.5}$ and AOD differ by region and have to be characterised using locally measured data as additional information. Aerosols have been well-observed over the ocean, where the surface is very dark except for sun glint. From an air-quality monitoring point of view, aerosol-related parameters have to be monitored over land, especially over large cities, where the surface albedo is relatively higher and finer spatial resolution is needed than over the ocean. 


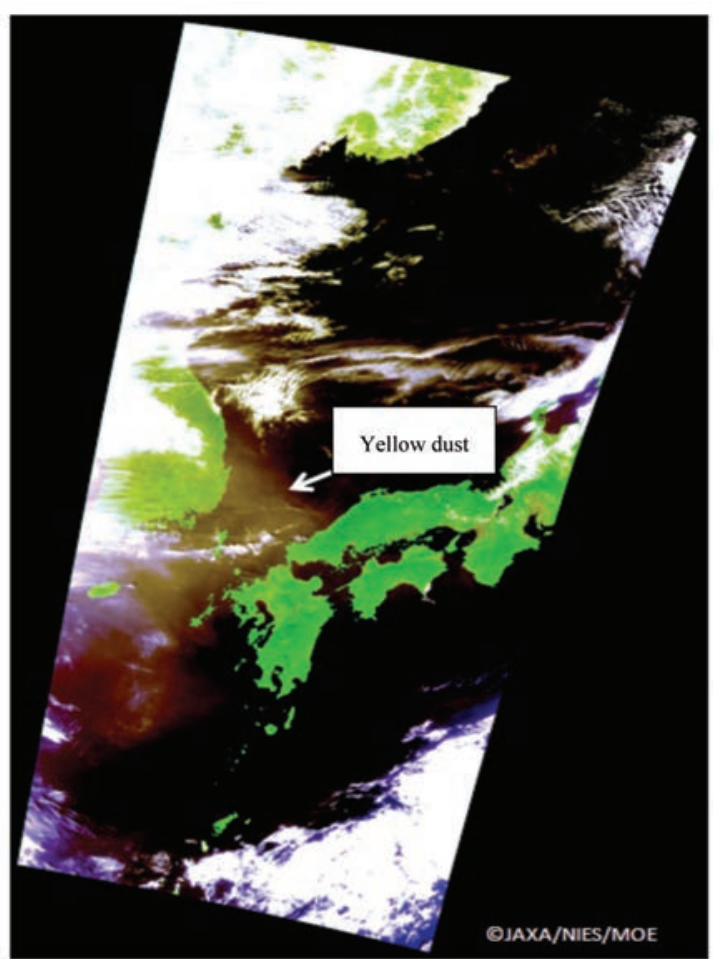

Fig. 5. Yellow dust over land and ocean measured by TANSOCAI on GOSAT on 19 March, 2013 (http://www.gosat.nies.go. jp/jp/related/2013/201303.htm).

Generally, surface reflectance is lower at shorter wavelengths. The second instrument TANSO-CAI onboard GOSAT has $380 \mathrm{~nm}$ band with a $500 \mathrm{~m}$ spatial resolution to demonstrate monitoring of thick AOD over a large city (Fukuda et al., 2014). SGLI onboard GCOM$\mathrm{C}$ also has a shortwave band of $380 \mathrm{~nm}$ with a higher spatial resolution of $250 \mathrm{~m}$ (Tanaka et al., 2010). It has three angles $(0,60,120$ degrees), polarisation and offnadir observation capability and this is expected to greatly improve aerosol observations over land.

Many heavy molecules have absorption bands in the UV region. When spectral radiance is bright enough with moderate absorption, the column-integrated number of molecules in the atmosphere can be retrieved. Atmospheric molecules of $\mathrm{O}_{3}$ and $\mathrm{NO}_{2}$ can be measured by absorption in the UV and $450 \mathrm{~nm}$ regions, respectively. The existing space-borne diffraction grating spectrometers cover the wide spectral bands of $\mathrm{O}_{3}$ and $\mathrm{NO}_{2}$ simultaneously. The spectral radiance of the $\mathrm{UV}_{3}$ band is weaker than visible light, so UV instruments need large instantaneous field of view (IFOV) and longer integration time to get enough signal level. Therefore, the spatial resolution is limited. In addition, it is difficult to design a diffraction grating system that has spectrally flat optical efficiency for wide spectral regions. As a result, opera- tional satellite data of larger than $10 \mathrm{~km}$ spatial resolution has not been fine enough to detect pollutant emission sources. If we target $\mathrm{NO}_{2}$ only, with much narrower spectral region, the efficiency of the diffraction grating can be maximised and spatial resolution can be improved. JAXA has started a feasibility study and laboratory experiments on a new imaging spectrometer to improve the spatial resolution of $\mathrm{NO}_{2}$ assessment to smaller than $3 \mathrm{~km}$.

The measurement method of aerosol properties has not yet been optimised. In addition to AOD, additional parameters such as size distribution should be investigated. $\mathrm{NO}_{2}$ and tropospheric $\mathrm{O}_{3}$ have been measured from space for the last decade but further optimisation and spatial resolution improvement is expected to be feasible.

\section{Acknowledgements}

The authors appreciate the research cooperation of $\mathrm{N}$. Minakawa and M. Hashizume, Institute of Tropical Medicine Nagasaki University (NEKKEN), in this study and the field work support by Nagasaki University Institute of Tropical Medicine - Kenya Medical Research Institute Project (NUITMKEMRI), in Nairobi and Mbita. We also thank M Moriyama and his Laboratory in the Graduate School of Engineering for the MODIS data processing for environmental analysis.

\section{References}

Boersma KF, Eskes HJ, Dirksen RJ, van der ARJ, Veefkind JP, Stammes P, Huijnen QL, Kleipool V, Sneep M, Claas J et al., 2011. An improved retrieval of tropospheric $\mathrm{NO}_{2}$ columns from the ozone monitoring instrument. Atmos Meas Tech 4, 1905-1928.

Burrows JP, Holzle E, Goede A, Visser PH, Fricke W, 1995. SCIAMACHY scanning imaging absorption spectrometer for atmospheric chartography. Acta Astronaut 35, 445-451.

Collins O, Cheruiyot EKG, Fusilli LS, Palumbo A, 2011. Development of an operational system for monitoring and predicting the aquatic plants proliferation in Lake Victoria. ESA TIGER initiative, looking after water in Africa. South Africa. TIGER II-PROJECT 18, 1-31 pp.

Frankenberg C, Hasekamp O, O’Dell C, Sanghavi S, Butz A, Worden J, 2012. Aerosol information content analysis of multi-angle high spectral resolution measurements and its benefit for high accuracy greenhouse gas retrievals. Atmos Meas Tech 5, 1809-1821.

Fukuda S, Nakajima T, Takenaka H, Higurashi A, Kikuchi N, Nakajima TY, Ishida H, 2013. New approaches to removing cloud shadows and evaluating the $380 \mathrm{~nm}$ surface reflectance for improved aerosol optical thickness retrievals from the 
GOSAT/TANSO-Cloud and Aerosol Imager. J Geophys Res Atmos 118, 13520-13531.

Hashizume M, Faruque ASG, Terao T, Yunus M, Streatfield K, Yamamoto T, 2011. The Indian Ocean dipole and cholera incidence in Bangladesh: a time-series analysis. Environ Health Perspect 119, 239-244.

Hashizume M, Terao T, Minakawa N, 2009. The Indian Ocean dipole and malaria risk in the highlands of western Kenya. PNAS 106, 1857-1862.

Kuze A, Suto H, Nakajima M, and Hamazaki T, 2009. Thermal and near infrared sensor for carbon observation Fourier-transform spectrometer on the Greenhouse Gases Observing Satellite for greenhouse gases monitoring. Appl Opt 48, 6716-6733.

Minakawa N, Dida GO, Sonye GO, Futami K, Njenga SM, 2012. Malaria vectors in Lake Victoria and adjacent habitats in Western Kenya. PLoS One 7, e32725.

Munro R, Eisinger M, Anderson C, Callies J, Corpaccioli E, Lang R, Lefebvre A, Livschitz Y, Perez Albinana A, 2006. GOME-2 on MetOp. From: In-Orbit verification to routine operations. In: proceedings of EUMETSAT meteorological satellite conference, Helsinki, Finland, 12-16 June 2006.

Sasano Y, Suzuki M, Yokota T, Kanzawa H, 1999. Improved limb atmospheric spectrometer (ILAS) for stratospheric ozone layer measurements by solar occultation technique. Geophys Res Lett 26, 197-200.

Tanaka K, Okamura Y, Amano T, Hiramatsu M, Shiratama K, 2010. Operation concept of the second-generation global imager (SGLI). Proc SPIE 7862, 1-6.

van Donkelaar A, Martin RV, Park RJ, 2006. Estimating ground-level $\mathrm{PM}_{2.5}$ using aerosol optical depth determined from satellite remote sensing. J Geophys Res 111, D21201.

Wesolowski A, Eagle N, Tatem AJ, Smith DL, Noor AM, Snow RW, Buckee CO, 2012. Quantifying the impact of human mobility on malaria. Science 338, 267-270.

WHO, 2006. WHO air quality guidelines for particulate matter, ozone, nitrogen dioxide and sulfur dioxide: global update 2005. Summary of risk assessment. Geneva, World Health Organization, 1-20 pp. 